\title{
The Primarily Explored Evaluation System of the Quality of Ground-stalled Employment
}

\author{
DENG Yonghui ${ }^{1, \mathrm{a}}$, HouTianYing ${ }^{2, \mathrm{~b}^{*}}$ \\ ${ }^{1}$ School of Finance and Public Administration, Harbin Business University, Harbin, Heilongjiang, China \\ ${ }^{2}$ School of Finance and Public Administration, Harbin Business University, Harbin, Heilongjiang, China \\ a73dengyonghui@163.com \\ b*1372916385@qq.com
}

\begin{abstract}
According to the Ilo Regulations on the employment of persons, the stall is a form of employment, can be called the stall-type employment. This ancient form of employment not only can maintain the livelihood of vulnerable groups, but also has low-threshold entrepreneurial attributes, characterized by strong flexibility and risk-control. Under the background of the extensive increase of informal employment in the world, in the special period after the new crown epidemic, we fully understand the rich and colorful ground-based employment, and construct the quality evaluation system of this kind of entrepreneurial employment is conducive to re-understanding the ground-based employment and help the ground-based employment management.
\end{abstract}

Keywords: ground-stalled employment, quality of employment, evaluation of the quality of employment.

\section{地推式就业的质量评价体系初探}

\author{
${ }^{1}$ 哈尔滨商业大学财政与公共管理学院，哈尔滨，黑龙江，中国 \\ ${ }^{2}$ 哈尔滨商业大学财政与公共管理学院, 哈尔滨, 黑龙江, 中国 \\ "73dengyonghui@163.com \\ b*1372916385@qq.com
}

邓永辉 $1, \mathrm{a}$ 侯天荣 $2, \mathrm{~b}^{*}$

\section{摘 要:}

依据国际劳工组织关于就业者的规定，摆摊是就业的一种形式，可以称为摆摊式就业。这种古老的就业形式不 仅能够维持弱势群体的生计，也具有低门槛的创业属性，显著特征就是灵活性强且风险易控性。在全世界非正 规就业广泛增加的背景下, 在新冠疫情后的特殊时期, 充分了解丰富多彩的地摊式就业, 构建这种创业式就业 的质量评价体系，有利于重新认识地推式就业，助力地摊式就业治理。

关键词: 地摊式就业; 就业质量; 就业质量评价

\section{1.引言}

国际劳工组织规定, 凡是在规定年龄内, 具有以 下情况的都属于就业者: (1)在规定时间内正在从事有 报酬或收入之职业的工作人员; (2)有职业, 但因为各 种原因没有工作的人; (3)雇主和个人经营者, 以及在 规定时间内为家庭企业或农场工作不少于正常工作 时间的 $1 / 3$ 的无报酬家庭工作人员; (4)已办理离休、 退休、退职手续, 但又再次从业 (有酬或自营等各种
方式）的人员。按照国际劳动组织对就业者的规定， 司空见惯的摆摊其实是一种就业形式, 其获得经营收 入或工薪报酬收入属于有收入的社会劳动, 可以称为 地摊式就业。

一般地, 地推式就业具有灵活性强、主动型强、 门槛相对低的特点。从以往经验来看, 摆摊式就业常 常是创业的初始形态，是小本经营、维持生计为目的 的生存型创业, 是劳动者通过周密卙酌、辛苦耐劳、 积累资本式创业的源头，具有风险易控性。因此，地 
摊式就业是兼具灵活就业和创业式就业的一种就业 形式。2020 年, 新冠疫情突如其来, 给经济系统、产 业结构及劳动力市场带来巨大冲击, 餐饮、航空、旅 游、零售等行业的依赖型群体收入呈断崖式下跌。两 会上, 总理对地推经济的认可使地摊式就业一夜爆红。 为疫情后流动受抑制、劳动力市场需求弱化的特殊时 期增加了一条就业渠道, 是保有劳动力供给数量、保

\section{2. 文献综述}

\section{1 关于地推式就业的相关研究}

按照是否有雇佣主体和法定就业权益保障, 就业 可以分为标准就业和非正规 (灵活) 就业, 地摊式就 业作为后者之中的一种, 国外研究主要围绕其与城市 规划和管理的关系展开，如欧共体成立的专家小组 (1993) 发布的《可持续的城市规划: 第一份报告》 中, 在英国城乡规划协会可持续发展研究小组 (1993) 发布的《可持续环境的规划对策》中, 均从城市可持 续发展、城市环境规划方面解决城市流动摊贩的环境 卫生问题 ${ }^{[1]}$; 研究者过多关注街头摊贩的违规和偏差, 以及政府的惩罚职能, 但是, 推贩的脆弱性使他们更 需要赋权性和保护性的法律规制 ${ }^{[2]}$ (Chen \& Eds, 2020）。国内研究主要集中在治理方面, 如刘新宁 (2006) 从产权配置角度对摊贩进行长效治理机制 ${ }^{[3]}$; 林琳和马飞等 (2006) 认为摆地摊群体是社会弱势群 体的一部分 ${ }^{[4]}$; 王洛忠等（2006）认为城市政府应将 街头摊贩视为非正规就业的一种, 政府应为街头摊贩 提供小额贷款、培训、技术上方面的政策支持 ${ }^{[5]}$; 台 湾学者李常生等 (2007) 和刘新宇 (2007) 均从节假 日时间和城市公共空间资源配置方面支持地推式就

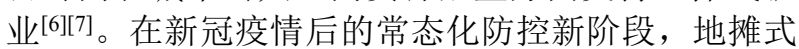
就业在增就业、拉消费、保民生、提升人间烟火气等 质朴性方面得到赞誉 ${ }^{[8]}$ (刘佳，2020），也从“摆摊市 场分布图”[9] (李英锋, 2020)、智慧松绑[10] (王延伟,

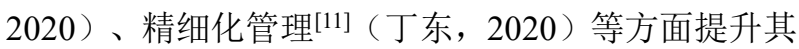
发展质量。

\section{2 关于就业质量评估体系的相关研究}

对就业质量的研究是劳动经济领域研究的一个 重点。国外与就业质量相近的研究包括美国的“工作 生活质量”、国际劳工组织的“体面劳动”等, 内容都 包括劳动报酬、工作条件、人际关系以及工作满意度 等宏观和微观指标; 我国在以及构建国内外与就业质 量相关的评估体系研究包括就业评估指标体系的研 究、关于特殊时期的就业政策及就业政策评估研究。 如 Main（1990）认为政府培训项目提高青年弱势群 体就业 ${ }^{[12]}$, Streeten（1981）要关注“工作中的穷人”; Greer (2020) 发现受新冠疫情冲击的美国失业者多为 有色人种。在就业困难的特殊时期, 各国政府都采取 积极的政策来拉动就业。如 20 世纪 90 年代德国施罗 德政府的短时工作制, 2008 年金融危机后日本增加临

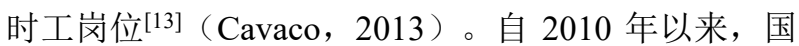

全劳动意识、保障基本民生和保住经济基本线的可行 渠道。那么，地摊式就业如何在多元化、多场景的灵 活就业中长久存在, 并在保证生计的基础上, 尽可能 地向创业式就业发展, 需要从地推式就业的支持政策 评价、生态效益评价、经济效益评价、社会效益评价 展开, 以充分了解丰富多彩的地推式就业, 构建这种 创业式就业的质量评价体系。

内关于重点群体的就业质量评价研究在增多, 与地推 式就业质量评价相关的研究主要针对新生代农民工 群体展开, 早期的研究集中在就业指标体系的构建, 后期的研究则结合依据调查数据, 运用层次分析法进 行定量评价。如对新生代农民工就业能力评价 ${ }^{[14][15]}$

（罗恩立，2010；高建丽等，2013），对新生代农民 工就业质量及自我感知进行评估 ${ }^{[16]}$ (罗文剑, 2018); 也有对灵活就业政策效果的评估 ${ }^{[17]}$ (吴江，2019）、 创业带动就业评估 ${ }^{[18]}$ (谭永生, 2020) 等多角度的评 估研究。

当前, 在经济社会常态下对地摊经济以及地摊式 就业的研究较多, 面对疫情冲击, 学者们认为其具有 稳就业、保民生等作用, 但需要智慧治理和引导。在 疫情冲击就业的特殊时期, 地摊式就业作为多渠道灵 活就业的一种, 通过充分认识和了解, 取其精华、去 其不足，从常态化发展的民生工程和和谐社会视角， 评价其就业质量，有利于持久地丰富就业生态，带动 多元化消费。

\section{3. 地推式就业的特点}

虽然地推经济作为是后疫情时期成为一个人们 关注的现象，但是地推经济是传统的经济模式。从纵 向的历史进程看，我国各个朝代的繁荣都与集市的繁 荣相连; 从横向的国别情况看, 无论是发达国家还是 发展中国家, 集市中都存在着广泛的地推式就业, 具 有相对独特的就业样貌, 遵循相对独特的规则, 满足 了多层次的消费需求。

\section{1 地推式就业的地点是集市等公共空间}

作为人们面对面交易的场所，地摊式就业的场所 是社区的公共空间为主，是居民十几分钟经济圈的组 成部分，如我国城市乡村的已有的固定早集市和晚集 市, 固定的生鲜市场以及商贸市场, 中东、南亚和东 南亚国家等城市销售蔬果、小吃等“巴刹”（市场）等 全天式的市场, 都是容纳地推式就业的场所。由于疫 情带来对就业的冲击, 加入地摊式就业的人们的增多, 集市的原有地理边界在扩展, 出现了临时聚集而成的 集市，允许在居民居住区临时占道摆摊。

\section{2 地推式就业的时间独特}

相对于标准的全日制就业时间，地摊式就业的时 间具有独特性，不仅由于集市的地点、面向人群而异， 也与从事的行业相关。常见的地推式就业所在的行业 
包括餐饮类、零售类和生活服务类。从就业所在的地 点看，在固定的集市具有全天候的固定营业时间外。 在常见的早间集市和晚间集市, 以北方城市哈尔滨为 例，摆摊和收摊时间则是就业者依据买卖多少的需求 自定，基本的原则是不影响日间的交通和市容。从这 一点看, 地摊式就业是标准就业之外的非主流就业。

\section{3 地摊式就业主体的包容性强}

从年龄上看, 地推式就业的人们从青少年到古稀 之年，如郑州 94 岁的“煎饼奶奶”，每天半夜 12 点到 次日凌晨 5 点在路边摆推卖煎饼, 一句“人活着总要 为自己找点价值”而火遍互联网，被人民日报点赞; 从性别上看, 地摊式就业主体没有明显的性别差异; 只要是有意愿、有勇气, 有摆推就业的能力, 就可从 事地摊式就业。”

\section{4. 地推式就业质量评价体系的构建思路}

地推式就业作为灵活就业的一种, 发展前景具有 稳定性。这样的判断来自于 20 世纪 70 年代以来“非 全职、非全时、非典型” 灵活就业增多的事实。在中 国, 依据《2019 年度人力资源和社会保障事业发展统 计公报》显示, 2019 年末全国城镇就业人口 44247 万人, 按照基本社会保险中覆盖率最高的基本养老保 险计算, 参加城镇职工基本养老保险的比例占城镇就 业人数的 $70.5 \%$, 说明有 13070 万人在城镇从事灵活 就业。在疫情后的特殊时期, 地推式就业明显增多的 背景下, 从以下四个方面构建评价体系 (如表 1 所示), 思考周边习以为常的地推式就业质量, 具有现实意义。

\section{1 政策支持评价维度}

2020 年, 新冠疫情对经济冲击和不确定性加大。 3 月 15 日, 成都市发布《成都市城市管理五允许一坚 持统筹疫情防控助力经济发展措施》, 开启了支持地 摊式就业的先河； 3 月 18 日，国务院办公厅印发《关 于应对新冠肺炎疫情影响强化稳定就业举措的实施 意见》, 提出“支持多渠道灵活就业, 合理设定无固 定经营场所推贩管理模式”; 5 月 28 日, 李克强总理 回答中外记者提问时提到, “西部有个城市, 按照当 地的规范, 设置了 3.6 万个流动商贩的推位, 结果一 夜之间有 10 万人就业。”之后, 各城市陆续出台扶持 地推经济的政策, 为地推式就业提供了有力支持。评 价国家和地方政策“组合拳”对地推式就业的影响, 是 新冠疫情后地摊式就业评估的基本内容。

\section{2 经济收益评价维度}

经济收益评价维度是反映当地发展地摊经济的 脱贫效应最直接的指标, 也是决定地摊经济能否在该 区域生存、发展下去的重要指标。后疫情时期, 社会 既需要专注于第四次工业革命、互联网技术、导航定 位系统的高精尖式就业, 也需要小美专、主体包容度
强的平民大众式就业。地推式就业在正规就业岗位不 足的时候实现劳动力让渡的迫切性、不可储藏性和专 用性, 让摆摊者的劳动能力获取经济收益; 同时, 对 地推商品及服务的定位、销售、模式、如何能够畅销, 都需要缜密的思考和实践的考察, 会让地推式就业的 劳动力在 “干中学” 中增值, 为劳动力市场以及商品市 场的供给侧改革助力。

由于地推式就业无偿或者低成本地使用社会公 共空间, 降低了地推成本, 提升了生计的收益, 使其 成为创新创业的商业试验场和睬化器。现有的烧烤、 玉林串串香、香蕉糕、钢管厂串串等佼佼者, 都是由 街头美食成长为登堂入室的餐饮品牌。

\section{3 主观感受评价维度}

人是生活在自己编织的意义之网之中的动物。在 开放自由的市场经济条件下，地推式就业使摆推者拥 有对生活的掌控感和力量感。在经济交易中积累自身 财富，在社会认可中认可自己，会赋予人积极努力的 价值观和精神风貌。地摊式就业提供的诚实劳动、高 于同行产品质量且适切市场需求的商品、服务和价格, 满足了大规模、多样化的需求, 增进了消费者的福利。

正如 2014 年李克强总理在首届中国质量(北京) 大会上讲话时强调的, 市场经济是讲道德、讲诚信的 经济。在现实中, 诚信的地摊式就业能够赢得市场的 认可, 在供求的频繁匹配和优胜劣汰下, 客观地带动 社会风气向着诚信、创新的方向发展。

\section{4 社会效益评价维度}

社会效益评价维度是评价地推式就业是否影响 地区自然环境和社会环境的维度, 同时也是衡量地推 式就业对社区和谐程度影响的重要指标。在社区范围 内面对面的市场交易, 地推式就业塑造了微观的社区 经济生态, 为社区范围内的购物加入休闲、交往等社 会意蕴和社会交往, 视听丰富、是、以及嗅觉的亲切 感, 所以总理称为人间烟火。

\section{5. 结论}

地摊式就业作为兼具技术范式和经营范式的就 业形式, 对于大多数地推式就业人员, 只要勤快实干, 就完全能够维持家庭生计, 促进自身经济收益和资本 积累的增加。所以从实践案例来看, 地摊式就业是践 行务实劳动、诚实劳动和踏实劳动的一个途径, 能提 升自信、满足感和获得感, 是奋斗幸福观的就业实践。

\section{REFERENCES}

[1] Andrew Blowers etc. Planning for a Sustainable Environment $[\mathrm{M}]$.London:EarthscanPublicationsLtd .1993.

[2] The Informal Economy Revisited: Examining the Past, Envisioning the Future. (2020). (M. A. Chen 
\& F. Carré Eds.). London and New York: Routledge.

[3] Liu Xinyu. Analysis of the Economics of Property Rights of Vendors, 2006 (11) : 129-131.

[4] Lin Lin, Ma Fei, Zhou Zilian. The characteristics and analysis of the phenomenon of urban "ghost walking"--take Guangzhou Newport West Road as an example, 2006 (2) : 90-96.

[5] Wang Luozhong, Liu Jinfa, Zong Ju. Urban Street Vendors: Informal Employment and Public Policy Responses. New Horizons, 2006 (2) : 66-68.

[6] Li Changsheng, Dong Wei. Discussion on the modernization of traditional retail markets and vendors in Taiwan's cities, 2007 (5) : 62-69.

[7] Liu Xinyu. On the Conflict between Employment in China's Low End Sector and Urban Environmental Management: Rethinking Development Strategies for Vendors: Shanghai: Fudan University, 2007.

[8] Liu Jia. Land-share economy and urban management, 2020 (9): 1

[9] Wang Yanwei." The land-share economy "should be developed with high quality, 2020 (7) : 22-23

[10] Li Yingfeng. The land-stalling economy requires the official version of the "market distribution map" (J) chinese employment, 2020 (7) : 1

[11] Ding Dong." The land-stalling economy "cannot be separated from fine management, 2020 (7) : 63-64

[12] Main, B.G. M., Shelly, M.A. The Effectiveness of the Youth Training Scheme as a ManpowerPolicy[J].Economica, 1990 ,57(228):495-514.

[13] Cavaco, S.Fougère,D.Pouget, J. Estimating the Effect of a Retraining Program on the Re-Employment Rate of Displaced Workers[J]. Empirical Economics, 2013, 44(01):261-287.

[14] Ronny. Study on the evaluation index system of the employability of the new generation of migrant workers. Journal of East China University of Technology (Social Science Edition), 2010 (1) : 13-19.

[15] Gao Jianli, Zhang Tongquan. The construction of the quantitative evaluation system of the employability of the new generation of migrant workers, 2013 (2) : 99-103+109.

[16] Luo Wenjian, Zhang Xiaochen, Lu Hua. Evaluation of the quality of employment of migrant workers in the central region under the background of the new normal situation:an empirical study based on D-AHP, 2018, 11 (02) : 165-180.

[17] Wu Jiang. New Era Promotion of Flexible Employment Policy and Evaluation of its Implementation Effect, 2019 (2) : 105-112.

[18] Tan Yongsheng. The study of the measurement evaluation and realization path of higher quality and fuller employment in China,2020 (05): $82-90+101$.

[19] Look at the Express. How much money do you make at night stalls, breakfast stalls, and ground stalls?

[EB/LO].https://kuaibao.qq.com/s/20180831A1HA E200?refer $=$ spider 